\title{
DELICATE NEEDLE WITH THE FINEST GAUGE FOR A BUTTERFLY GLAND, THE THYROID: IS IT WORTH MENTIONING?
}

\author{
Sengul Ilker, ${ }^{1,2}$ Sengul Demet ${ }^{3}$ \\ ${ }^{1}$ Division of Endocrine Surgery, Giresun University Faculty of Medicine, Giresun, Turkey \\ ${ }^{2}$ Department of General Surgery, Giresun University Faculty of Medicine, Giresun, Turkey \\ ${ }^{3}$ Department of Pathology, Giresun University Faculty of Medicine, Giresun, Turkey
}

Primljen/Received 02. 07. 2020. god.

Thyroidology has yet to declare the optimal needle size for thyroid fine-needle aspiration (FNA) cytology. In this respect, the researches on this issue remain restricted in English-language literature. Currently, Saraph and colleagues (1) evaluated dissimilarity between 23- and 25-gauge needles in terms of nondiagnostic/unsatisfactory rates of The Bethesda System for Reporting Thyroid Cytopathology (TBSRTC) after FNA applications. The authors had worked with a sum of 14123 -and 15725 -gauge needles and reported their nondiagnostic/unsatisfactory rates as $31.09 \%$ and $35.07 \%$, respectively, with no statistical difference. However, Dong et al. (2) reported working with 240 consecutive nodules, had undergone US-guided FNA (US-FNA), and obtained the highest scores of sample quality with 25 -gauge needles in thyroid FNA cytology, comparing with 22- and 23-gauge needles, very recently. The authors declared the nondiagnostic scores of $15.42 \%, 19.58 \%$, and $14.17 \%$ for US-FNA with 22-, 23-, and 25-gauge needles, respectively (2). In addition, recently, Shumrick et al. (3) reported 148 thyroid nodules in 107 cases, had undergone US-FNA, revealing significantly less non-diagnostic cytology with 27 -gauged needles, $11.3 \%$, comparing 25 -gauge needles, $24.7 \%$. We recently have studied the possible impact of size cutoff of 10 - and $15-\mathrm{mm}$ for the thyroid nodules on three diagnostic tools; i) strain elastography (SE), ii) sonography-guided FNA cytology, and iii) histopathology. A sum of 425 cases with 500 thyroid nodules had undergone US-guided FNA (USFNA) with 27-gauge finest-needle by a single surgeon (I.S.), surgeon-performed US (SUS), with a local anesthetic agent (1-3 $\mathrm{mL}$ of $1 \%$ lidocaine with 1:100,000 epinephrine) based on American Thyroid Association (ATA) management guidelines for patients with thy-
Prihvaćen/Accepted 03. 08. 2021. god.

roid nodules and differentiated thyroid cancer [i.e. low, intermediate, and high suspicion nodules]; 2015 ATA management guidelines for adult patients with thyroid nodules and differentiated thyroid cancer] for three years and two months. TBSRTC 1st ed. had been used for this period, for the mentioned considerable and novel 'SUS based' US-FNA terminology with the specific and also 'well-accepted and crucial' size cut offs of 10- and 15- $\mathrm{mm}$ in Thyroidology revealing the FNA cytology outcomes with27-gauge fine needles, for Category I, per se, TBSRTC, 1 st ed. were revealed as $9.0 \%$ (4). Moss et al.(5) notified that regular and coordinated thyroid FNA should be performed with smaller needle gauges, 24-27-gauges, without aspiration, routinely, in a systematic review and meta-analysis. Saraph et al. (1) specified the utilization of a 25 -gauge needle did not produce a lower nondiagnostic rate, comparing the 23 -gauge one. In addition, they pointed out that larger nodules might increase diagnostic rates, while the older and cystic nodules are prone to inadequate samples. We agree with Saraph and colleagues'(1) opinion about the limitations of nodule location, such as a posterior, more difficult to reach nodules, and sonography of composition (mixed and solid) and echogenicity which may be crucial parameters for this issue. Nonetheless, we postulate that the so-called needle gauge concept selectively enriches with finer needles. Additionally, we currently introduced the proposal of a novel terminology, "minimally invasive FNA (MIFNA)" and "minimally invasive thyroid FNA; Thyroid MIFNA (Thy MIFNA)", including 27-gauge fine-needle with pre-procedural topical and local anesthetic agents administration, hope to contribute in Thyroidology (6). Of note, we might recommend opting for a 27-gauge 
finest needle in terms of US-FNA for a butterfly gland, the thyroid, with reasonable low rates of non-diagnostic/unsatisfactory cytology, TBSRTC, 1st and 2nd ed. and low severity of pain, as a matter of course. To this end, we also recommend: "think twice with larger needles for thyroid US-FNA”. This issue merits further investigation.

Keywords: Thyroid gland, Needle, Gauge, Optimal size, Fine-needle aspiration, Thyroidology.

\author{
Abbreviations \\ FNA - Fine-needle aspiration \\ US - Ultrasonography \\ SE - Strain elastography
}

\section{REFERENCES}

1. Saraph S, Cohen H, Ronen O. Effect of needle gauge on thyroid FNA diagnostic rate. Endocrine. 2021. Jun 19. doi: 10.1007/s12020-021-02797-9. Epub ahead of print.

2. Dong Y, Gao L, Sui Y, Mao M, Zhan W, Zhou J. Comparison of ultrasound-guided fine-needle cytology quality in thyroid nodules with 22-, 23-, and 25-gauge needles. Anal Cell Pathol (Amst). 2021; 2021: 5544921. doi: 10.1155/2021/5544921. eCollection 2021.

3. Shumrick CM, Simmonds JC, Ogden LL, Snowden CA, Dhingra JK. A blinded randomized trial comparing 2 needle gauges for Fine-Needle Biopsy of thyroid nodules. OTO Open. 2021; 5(2): 2473974X211013732. doi: 10.1177/2473974X211013732.

\author{
Correspondence to/Autor za korespondenciju \\ Demet Sengul, MD, Professor (Assoc) \\ Founder Chair, Department of Pathology \\ Founder Chair, Education and Research Laboratories \\ Giresun University Faculty of Medicine \\ Gazipasa Compound, Gazi Avenue \\ 28100 Giresun, Turkey \\ E-mail: demet.sengul.52@gmail.com \\ ORCID number: 0000-0002-0416-0621
}

ATA - American Thyroid Association

TBSRTC - The Bethesda System for Reporting Thyroid Cytopathology.

\section{Acknowledgment}

None.

Conflict of Interests: The authors declare that there are no conflicts of interest related to this article.

Funding: None

\section{Licensing}

This work is licensed under a Creative Commons Attribution 4.0 International (CC BY 4.0) License.

4. Sengul D, Sengul I, Egrioglu E, Ozturk T, Aydin I, Kesicioglu T, et al. Can cut-off points of 10 and $15 \mathrm{~mm}$ of thyroid nodule predict malignancy on the basis of three diagnostic tools: i) strain elastography, ii) the Bethesda System for Reporting Thyroid Cytopathology with 27-gauge fine-needle, and iii) histopathology? J BUON. 2020; 25(2): 1122-9.

5. Moss WJ, Finegersh A, Pang J, Califano JA, Coffey CS, Orosco RK, et al. Needle biopsy of routine thyroid nodules should be performed using a capillary action technique with 24to 27-gauge needles: a systematic review and meta-analysis. Thyroid. 2018; 28(7): 857-63. doi: 10.1089/thy.2017.0643.

6. Sengul I, Sengul D. Proposal of a novel terminology: Minimally invasive FNa and thyroid minimally invasive FNA; MIFNA and Thyroid MIFNA. Ann Ital Chir. 2021; 92:330-1. 